\title{
Article \\ Exploratory Analysis of Fundamental Spiritual Support Factors to a Positive Attitude in Patients with COVID-19 Using Natural-Language Processing Algorithms
}

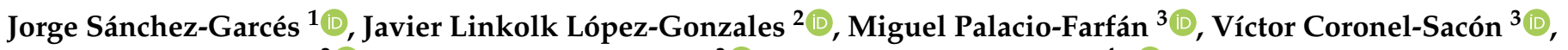 \\ Yonny Ferney-Teheran ${ }^{3}\left[\right.$, Jahisber Peñuela-Pineda ${ }^{3}\left[\right.$ and Himer Avila-George ${ }^{4, *} * \mathbb{C}$ \\ 1 E.P. Ingeniería de Sistemas, Facultad de Ingeniería y Arquitectura, Universidad Peruana Unión, \\ Lima 15, Peru; jasg@upeu.edu.pe \\ 2 E.P. Ingeniería Ambiental, Facultad de Ingeniería y Arquitectura, Universidad Peruana Unión, Lima 15, Peru; \\ javierlinkolk@gmail.com \\ 3 Facultad de Teología, Corporación Universitaria Adventista, Medellín 050022, Colombia; \\ mapalaciof@unac.edu.com (M.P.-F.); vxcoronels@unac.edu.co (V.C.-S.); yteheran@unac.edu.co (Y.F.-T.); \\ jpenuela@unac.edu.co (J.P.-P.) \\ 4 Departamento de Ciencias Computacionales e Ingenierías, Universidad de Guadalajara, \\ Guadalajara 46600, Mexico \\ * Correspondence: himer.avila@academicos.udg.mx
}

Citation: Sánchez-Garcés, J.; López-Gonzales, J.L.; Palacio-Farfán, M.; Coronel-Sacón, V.;

Ferney-Teheran, Y.; Peñuela-Pineda, J.; Avila-George, H. Exploratory Analysis of Fundamental Spiritual Support Factors to a Positive Attitude in Patients with COVID-19 Using Natural-Language Processing Algorithms. Appl. Sci. 2021, 11, 9524. https://doi.org/10.3390/app11209524

Academic Editor: Antonio Fernández

Received: 22 September 2021

Accepted: 11 October 2021

Published: 13 October 2021

Publisher's Note: MDPI stays neutral with regard to jurisdictional claims in published maps and institutional affiliations.

Copyright: (c) 2021 by the authors. Licensee MDPI, Basel, Switzerland. This article is an open access article distributed under the terms and conditions of the Creative Commons Attribution (CC BY) license (https:/ / creativecommons.org/licenses/by/ $4.0 /)$.

\begin{abstract}
The SARS-CoV-2 virus that causes COVID-19 affects the respiratory tract and is highly infectious. Those patients who knew that the disease could cause death or that their healing process is quite painful because of the symptoms and conditions developed extreme stress, anxiety, and depression, which aggravated the effects of the disease. Therefore, it is vital to conduct research to analyze these effects and generate self-help and support mechanisms during the disease process. This paper presents exploratory analysis related to stress, coping attitudes, emotional responses, and sources of support that were vital in patients affected by COVID-19; the focus of this study is the consideration of the spiritual factor, which may influence religious resilience that allows for a positive attitude and tenacity. To carry out this research, interviews were conducted with patients who had suffered from COVID-19 disease, and the collected information was processed using textmining techniques using a two-phase methodology. The first phase is based on the Colaizzi method. Interview responses were coded through the search for patterns in the key phrases, and these codes were grouped, forming semantic relationships. In the second phase, natural-language processing algorithms (WordCloud, WordEmbedding, sentiment analysis of opinions) were used, summarizing the interviews in relevant factors of the patient's experience during the disease. Spiritual resilience stood out the most of all key phrases of the code group tables. Likewise, words such as security, confidence, tranquility, and peace indicated that the patients took a positive attitude towards the symptoms and complications of the disease. Therefore, it is important to be the resilience to face a crisis process, and one of the factors that generated such resilience in COVID-19 patients was religious faith, which was expressed in the interviews using the factors of security, trust, promises of healing, tranquility, and the impossibility of discouragement. All this contributed to the positive attitude of the interviewees during the process of recovery from the disease.
\end{abstract}

Keywords: COVID-19; exploratory analysis; spiritual factors; WordEmbedding; word cloud

\section{Introduction}

In 2019, the SARS-CoV-2 virus appeared, which causes the COVID-19 disease. According to the World Health Organization (WHO), this virus affects the respiratory tract, and it is highly infectious and pathogenic, so it is vital to develop systems for monitoring patients with COVID-19 [1]. According to Praveen et al. [2], COVID-19 has caused stress, anxiety, depression, and trauma in patients and healthcare workers. In this regard, a study 
conducted by Lahiri et al. [3] indicated that those patients who knew that the disease could be a cause of death developed extreme stress, which was expressed by long periods of insomnia; such stress was exacerbated in those patients who lived alone and in the elderly. The study of Wang (2020) corroborated this finding. They surveyed 1210 people in 194 Chinese cities, and found that, at the beginning of the COVID-19 outbreak, more than $50 \%$ of the respondents had moderate-to-severe psychological impact, and $30 \%$ had mild-to-severe anxiety. On the other hand, the studies of Nguyen et al. [4], applied to 3947 participants from Vietnam, and Breen et al. [5] found that people who learned that they were suspected or confirmed cases with COVID-19 showed high levels of psychological stress, resulting from fear of terrible symptoms or excruciating death. Thus, while coping with COVID-19, the chemical processes in the body can trigger multiple neurological and psychiatric consequences, worsening the condition. In that sense, the disease has a very relevant psychological factor in the healing process, and that is why tranquility and a positive attitude are required [6].

Other contributions responded to the above problem, and addressed stress, depression, and anxiety issues that could be triggered by COVID-19 due to uncertainty (see Table 1). These studies describe techniques used to analyze the problem, such as naturallanguage processing (NLP) algorithms, word-cloud algorithms, and the semantic analysis of interviews through qualitative phenomenological analysis to explore text mining on the basis of obtaining information through Twitter or interviews with people who met the inclusion criteria of the study.

According to Salas-Zárate et al. [7], sentiment analysis in healthcare is of utmost importance. An opinion may contain positive or negative criticisms about different aspects of medicine or medical services. In this sense, feelings such as panic, stress, anxiety, loneliness, anger, anticipation, disgust, fear, joy, sadness, surprise, and confidence are analyzed in this paper. Likewise, phrases that generated panic, stress, anxiety, and behavioral changes during the pandemic were explored. Therefore, this study is based on the contributions of the aforementioned antecedents, with exploratory analysis being related to stress, assumed attitudes, emotional responses, and sources of support, such as the family, which were vital during the pandemic crisis.

The particular focus of this study is the consideration of the spiritual factor, which allowed for a positive attitude of courage and tenacity. This scenario shows a broader perspective on the feelings of those who faced this disease, with a tinge of hope imbued through their beliefs in God. Each structured and semistructured interview was accompanied by a biblical text used by the Christian community, Psalm 23. This study involves COVID-19 patients from Ecuador and Colombia, where experiences in different cultural contexts were recorded. For the exploratory study of the interviews, a series of tools for information processing (text mining) were used, categorized in NLP algorithms (sentiment analysis, WordEmbedding, Word Cloud) and coding the responses of the interviewees (coding or key phrases of interview responses, grouping of codes, and Sankey diagrams). These tools added up to the final interpretation of how the disease occurred in these patients, allowing for having a clearer perspective on the generated feelings while facing the disease, including emotional and spiritual factors such as security, hope, and certainty, which conditioned a better attitude despite the suffering that they described during the disease process. Our contributions are summarized below:

- Semantic similarity analysis of the keywords found in interviews of COVID-19 patients was carried out.

- Sentiment analysis of produced emotions during the disease was carried out, finding low positive polarity and medium-high level of subjectivity, which shows that the answers had a positive attitude, and expressed very personal beliefs and ideas that were sufficient to face the disease process.

- The spiritual resilience factor is highlighted as the main factor found during the responses and as responsible for the positive attitude. 
Table 1. Representative publications that addressed the COVID-19 issue from a computational model.

\begin{tabular}{|c|c|c|c|}
\hline Proposal & Techniques & Results & Reference \\
\hline Sentiment analysis of sentences obtained from tweets. & TextBlob, Word Cloud. & $\begin{array}{l}\text { The study of } 2 \text { datasets observes the impact of social } \\
\text { networks that generate insecurity and uncertainty } \\
\text { regarding COVID-19. }\end{array}$ & Alamoodi et al. [8] \\
\hline $\begin{array}{l}\text { Understanding the role of sentiment analysis and } \\
\text { opinion mining in COVID-19. }\end{array}$ & $\begin{array}{l}\text { Paragraph vector (Doc2Vec), word cloud, } \\
\text { and Gaussian fuzzy logic. }\end{array}$ & $\begin{array}{l}\text { A systematic study to understand statistics and } \\
\text { keywords about COVID- } 19 \text {. }\end{array}$ & Chakraborty et al. [9] \\
\hline $\begin{array}{l}\text { Using NLP to identify aspects causing the most stress, } \\
\text { anxiety, and trauma in Indian citizens by COVID-19. }\end{array}$ & Machine learning, TextBlob. & $\begin{array}{l}\text { General public's attitude towards stress. Anxiety also } \\
\text { had no change in the last part of the study. }\end{array}$ & Praveen et al. [2] \\
\hline $\begin{array}{l}\text { To explore the psychology of patients with COVID-19 } \\
\text { during hospitalization. }\end{array}$ & $\begin{array}{l}\text { Phenomenological technique with } \\
\text { semistructured interviews. }\end{array}$ & $\begin{array}{l}\text { To develop an attitude to face the disease despite fear } \\
\text { and uncertainty. }\end{array}$ & Sun et al. [10] \\
\hline $\begin{array}{l}\text { Identifying key areas of loneliness in diverse } \\
\text { communities during the pandemic through data } \\
\text { mining on the social network Twitter. }\end{array}$ & $\begin{array}{l}\text { Machine learning (theme modeling), hierarchical } \\
\text { modeling, topic modeling, and NLP. }\end{array}$ & $\begin{array}{l}\text { Addresses novel problems such as loneliness during } \\
\text { COVID-19 and the potential utility of evolving } \\
\text { mental-health problems. }\end{array}$ & Koh and Liew [11] \\
\hline $\begin{array}{l}\text { Explored the dynamics and flow of behavioral } \\
\text { changes among Twitter users during the pandemic. }\end{array}$ & NLP and social-network analysis techniques. & $\begin{array}{l}\text { The percentage of tweets with negative sentiment in } \\
\text { all intervals exceeded that of positive and neutral } \\
\text { sentiments. Furthermore, while negative tweets had a } \\
\text { continuous decline, neutral and positive tweets } \\
\text { followed a fluctuating trend. }\end{array}$ & Kaur et al. [12] \\
\hline $\begin{array}{l}\text { Identified emotions that dominated citizens in the } \\
\text { pandemic from millions of tweets in Portuguese } \\
\text { (Brazil) and English (US), and sentiment analysis. }\end{array}$ & $\begin{array}{l}\text { NLP, NLTK, WordNetLemmatizer, classifier of } \\
\text { logistic regression, word cloud, and pyLDAvis tool. }\end{array}$ & $\begin{array}{l}\text { The study demonstrated the economic impact, policy, } \\
\text { treatments, and reports on anxiety caused } \\
\text { by confinement. }\end{array}$ & Garcia and Berton [13] \\
\hline $\begin{array}{l}\text { Analyzing tweets between } 25 \text { and } 28 \text { March to } \\
\text { measure feelings about confinement. }\end{array}$ & R software and word cloud. & $\begin{array}{l}\text { The study showed that, despite negativity, fear, } \\
\text { disgust, and sadness about the lock-in, the prominent } \\
\text { sentiment was positive, followed by confidence and } \\
\text { commitment from citizens to lower the spike } \\
\text { in contagions. }\end{array}$ & Barkur et al. [14] \\
\hline $\begin{array}{l}\text { Explored and compared the impact of the pandemic } \\
\text { (perceived stress, risk, and fear of being infected, } \\
\text { estimated severity, compliance with containment, } \\
\text { quality of life, quality of relationships, loneliness, } \\
\text { resilience) on a sample of French and Reunion Island, } \\
\text { the most populous overseas department, citizens. }\end{array}$ & Questionnaire on the Internet and validation scales. & $\begin{array}{l}\text { Results reflect significant differences between the two } \\
\text { samples. Comparisons indicate that the metropolitan } \\
\text { sample had significantly higher perceived risk, } \\
\text { confinement compliance, and loneliness scores. }\end{array}$ & Laconi et al. [15] \\
\hline
\end{tabular}


Table 1. Cont.

\begin{tabular}{|c|c|c|c|}
\hline Proposal & Techniques & Results & Reference \\
\hline $\begin{array}{l}\text { Sentiment analysis of the reaction to COVID-19 in } \\
\text { various tweets. }\end{array}$ & Machine learning and sentiment analysis. & $\begin{array}{l}\text { Sentiments were mostly positive and indicated that, } \\
\text { despite the quarantine, people were looking forward } \\
\text { to a different experience and saw it as an opportunity } \\
\text { to socialize with family. }\end{array}$ & Bhat et al. [16] \\
\hline $\begin{array}{l}\text { Analyzed specific microblogging content (WeChat) } \\
\text { and feelings related to COVID- } 19 \text {. }\end{array}$ & NLP. & $\begin{array}{l}\text { Demonstrated the effectiveness of the proposed } \\
\text { method that detects misinformation about COVID-19, } \\
\text { as many of the posted sentences were not true. }\end{array}$ & Ayoub et al. [17] \\
\hline $\begin{array}{l}\text { Analyzed multimodal textual data contained in } \\
\text { real-time tweets related to COVID-19. In addition, } \\
\text { this article studied a scale of eight emotions (anger, } \\
\text { anticipation, disgust, fear, joy, sadness, surprise, } \\
\text { and confidence) over multiple categories such as } \\
\text { nature, confinement, health, education, market, } \\
\text { and politics. }\end{array}$ & NLP. & $\begin{array}{l}\text { Analysis showed that people were mostly very } \\
\text { patient during the lock-in period and contributed to } \\
\text { stopping the chain of COVID-19 spread. They } \\
\text { showed confidence in government policies and } \\
\text { decisions. Most people were afraid and insecure } \\
\text { about the results of the lock-in. Unemployment, } \\
\text { working from home, the declining economy, and the } \\
\text { loss of close ones affected people's emotional health. } \\
\text { Despite all the shortcomings, people attempted to } \\
\text { look on the bright side of things. }\end{array}$ & Gupta et al. [18] \\
\hline
\end{tabular}


The remainder of the paper is structured as follows: Section 2 presents the developed methodology, which was based on an exploratory study described in two phases. Section 3 analyzes and compares the proposed processes. Section 4 presents the main findings and their comparisons in context. Lastly, Section 5 provides the main findings and illustrates future challenges.

\section{Materials and Methods}

\subsection{Sample}

The sample was nonprobabilistic, selected for the convenience of the researchers, where the ten selected patients had a complicated COVID-19 disease process in terms of their symptomatology. According to a report from Johns Hopkins University, they came from South American countries, such as Colombia and Ecuador, which are ranked 9th and 46th, respectively, in the number of deaths due to COVID-19 [19]. For the representativeness of the qualitative sample, patients were aged 25-84 years, and they were 5 men and 5 women.

Inclusion criteria were belonging to the Christian religion, and being an improving COVID-19 patient or having improvemee.

\subsection{Processing}

\subsubsection{Steps in Colaizzi's Descriptive Phenomenological Method}

The method consists of 7 steps to develop rigorous analysis (see Figure 1). The final result is the description of the study object. For this, the interviewee experiences are important, from which key phrases are obtained that help to formulate such a description. These phases are as follows.

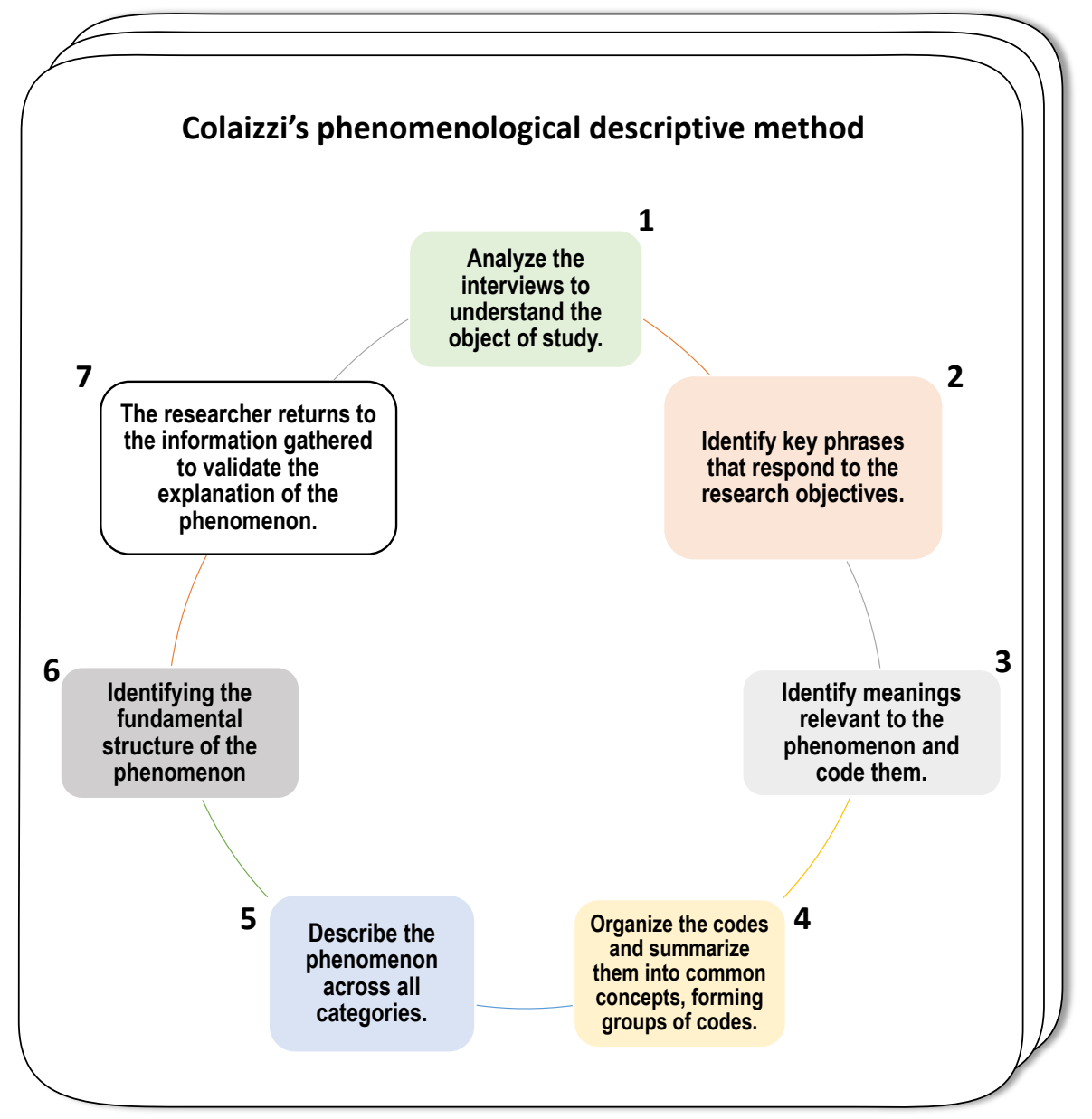

Figure 1. Colaizzi's descriptive phenomenological method. 
In this sense, this research used the first four steps of the present method, and Steps 5-7 were unified in Step 5, which consisted of the interpretation of the object of study. The following were used for the interpretation of Step 5: code group tables, Sankey diagrams, sentiment analysis, WordEmbedding, and word cloud [20,21].

\subsubsection{Textmining}

Text mining allows for deducing relevant factors in data expressed in text format; these factors describe trends that exist in the data, relationships that could not be manually observed due to the volume of data. These trends are interpreted thanks to techniques and tools used in text mining. They are also described as correlations that are exploited with mathematical models that process text-type data and are different from quantitative models. This process starts with the recovery and extraction of information from different data sources (interviews, big data, and bibliographic background), followed by naturallanguage processing that allows for the interpretation of facts, key data, and relationships between texts [22].

\subsubsection{Text Transform}

Before applying the NLP algorithms to the set of interview responses, they were first transformed to facilitate the interpretation of the input data. In that sense, the Natural Language Toolkit (NLTK) library, a platform that allows for the interpretation of human language, was used; characters were converted into lowercase. Subsequently, punctuation marks and stop words (sentence connectors) were eliminated, simplifying the language [23].

\subsubsection{WordEmbedding}

Distributional semantics consists of deducing the meaning of language through the numerical representation of the word (vector). This solves analogies such as:

$$
\text { COVID-19-Attitude }+ \text { Person }=\text { Success. }
$$

If it adds an excellent attitude in the person to the effects of the disease, then the chances of getting out of the crisis are quite high. Word2vec, created by Tomas Mikolov [24], was used to perform this word embedding analysis.

To develop this algorithm, they first found similar semantic features in the corpus of words and classified those words. Lee et al. [24] presented two architectures, continuous bag of words (CBOW) and skip-gram, to perform word classification. Both architectures are based on a neural network with a hidden layer. CBOW predicts a word on the basis of the context of words as input. Skip-gram maximizes the prediction of a word on the basis of another word in the same context; therefore, more distant words have less weight [25]. Bai et al. [26] proposed thematic similarity analysis, taking the same principles of vector representation for semantic analysis through analyzing the connotation and denotation of point to point in a sequence-to-sequence problem. This analysis is based on the CBOW model, which is more computationally efficient and suitable for a larger corpus, and this model was used here.

The algorithm was started by randomly taking a group of words from the corpus; the central word $(c)$ of that group is defined, and the remaining ofwords are called context words $\left(c_{1}, \ldots, c_{m}\right)$. A relation of both is obtained, allowing for predicting whether one word could have a possible relation with any other word $w$ (see Equation (1)).

$$
p\left(w \mid c_{1}, \ldots, c_{m}\right)=p(w \mid c),
$$

where $p$ is the probability of the relation. In this scenario, the question arises of how one can calculate the probability of a context word given the central word. Equation (2) answers this question.

$$
p\left(w_{o} \mid w_{c}\right)=\frac{\exp \left(u_{o}^{T} v_{\mathcal{c}}\right)}{\sum_{w=1}^{V} \exp \left(u_{w}^{T} v_{\mathcal{c}}\right)}
$$


where $V$ is the vocabulary, $w_{o}$ is a word context, $w_{c}$ is the central word, $U_{0}$ is the vector representation of the context word, $V_{c}$ is the vector representation of the central word, and $U_{w}$ is the vector representation when $w$ is a context word. The numerator consists of the scalar product of words $w$ and $c$, which describes the similarity between the two vectors; the higher the similarity between $u_{w}$ and $v_{w}$ is, the higher the probability. The denominator allows for normalizing the probability values across the vocabulary, so that everything sums to 1 .

\subsubsection{Sentiment Analysis}

According to Yadollahi et al. [27], sentiment analysis determines whether opinions about a topic under discussion are favorable; opinions generally show what the author thinks about a given topic, which is known as opinion mining. In this study, such analysis was conducted about the impact of a chapter of the Bible (Psalm 23), belief, and faith, on an atypical disease in its symptomatology. Thus, the purpose was to determine the attitude, which could be nuanced and complex, modeling it as a classification task with symbolic values, namely, as positive, negative, and neutral [9].

The used library was Python's TEXTBLOB with its default option PatternAnalyzer, which classifies on the basis of the pattern library, a predefined set of categorized words (NLTK database). Sentiments are defined on the basis of semantic relationships and the frequency of each word in an input sentence, which results in more accurate output. According to the research developed in [28], this type of algorithm is categorized as a corpus-based approach, which iteratively forms sets of positive and negative words, taking a large text corpus as the foundation. To perform this information clustering, opinion words were identified through syntactic patterns, the context of corpus words, the sequences of expressions, and a set of linguistic constraints following the method proposed by Hatzivassiloglou and McKeown [29] (see Equation (3)), where a function $\Phi$ was defined that scored each possible partition of the adjectives $(P)$ into two subgroups, $C_{1}$ and $C_{2}$.

$$
\Phi(P)=\sum_{i=1}^{2}\left(\frac{1}{\left|C_{i}\right|} \sum_{x, y \in C_{i}, x \neq y} d(x, y)\right),
$$

where $\Phi(P)$ is the function that scores each group of adjectives (positive and negative) represented by $C_{i}$, and represents the cardinality of cluster $i ; d(x, y)$ is the distinction or differences identified for a word to be placed in some group (positive or negative).

The procedure for determining polarity consists of constructing a first random partition of words to adjectives; then, in second, third, and n-th iterations, the word is located in the corresponding adjective. The $\mathrm{n}$-th iteration is given until no move can improve the objective function, and adjectives are well-organized.

\subsection{Methodology}

The methodology described in Figure 2 is composed of two phases. The first phase is described using the qualitative exploratory method of the information (interviews), using the phenomenological method whose purpose was to analyze the experiences of the interviewees concerning COVID-19, for which Colaizzi's method was used. The second phase consisted of interpreting the interviewees' experiences, for which natural-language processing algorithms such as sentiment analysis, word cloud, and word semantics (WordEmbedding) were used. 


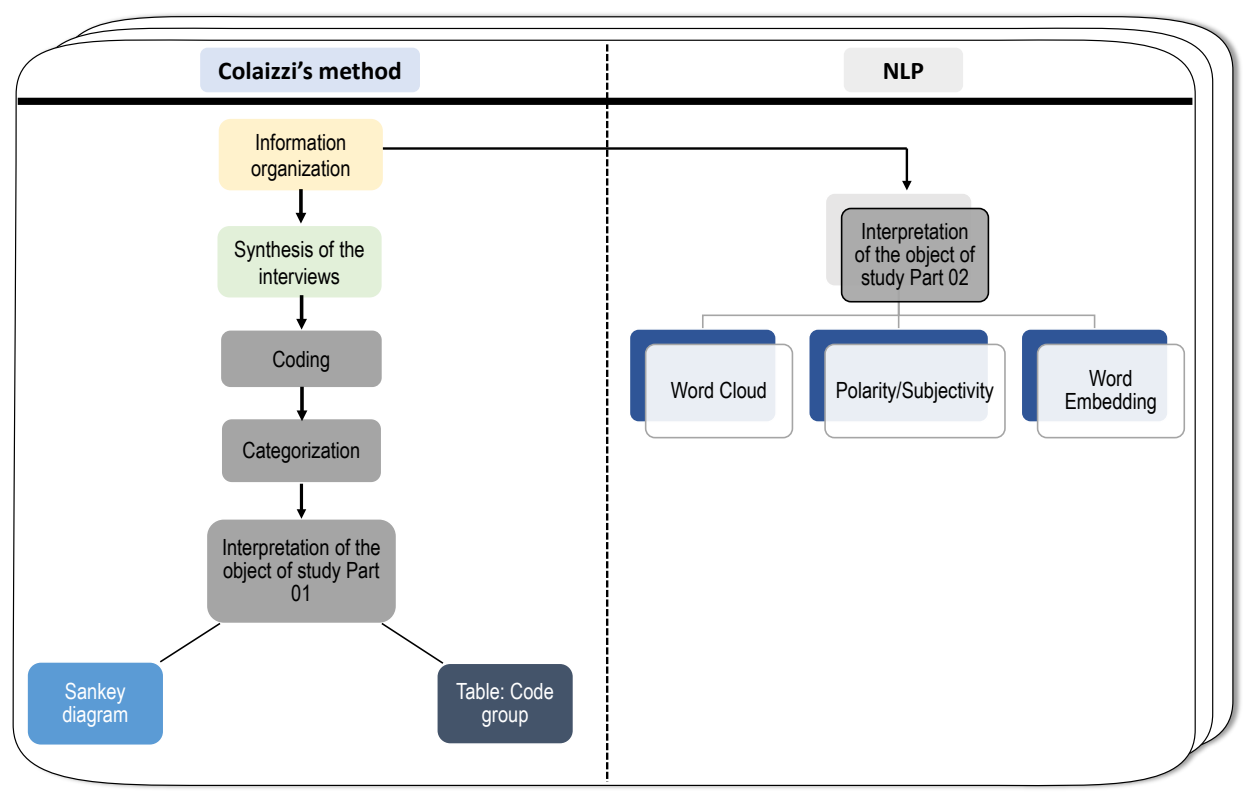

Figure 2. Research methodology.

\subsubsection{Colaizzi's Method}

1. Step 1: organization of information. Information was consolidated in a spreadsheet whose columns were interviewee code (names were avoided) and interviewee responses. This format was used to analyze the information, reviewing the responses several times to understand their meaning.

2. Step 2: interview synthesis. Key phrases were identified in the answers and organized in 6 iterations in each of the 10 interviewees. This phase is the familiarization of the researcher with the collected information (object of study), observing the relevant meanings of the phenomenon through the key phrases.

3. Step 3: coding. Key phrases were then called codes, and they summarized a whole answer with the meaning towards the object of study.

4. Step 4: categorization. Once the codes were identified, they were grouped into categories (common concepts) to form themes of the object of study.

5. Step 5: interpretation of object of study (Part 1). This interpretation described the number of times tat each of the interviewees cited the codes; Sankey diagrams illustrated these occurrences in the interviews. To interpret the semantic relationships between codes, common concepts that explained the relevant factors that made the patients triumph over the disease were formed.

\subsubsection{Step 5: Interpretation of the Object of Study (Part 02) Using NLP Algorithms}

The object of study was interpreted using NLP algorithms, which allowed for expanding the meaning and crossing information to consolidate interpretation. For this, we used: (1) the frequency of the words in the interviews through the Word Cloud graph, (2) sentiment analysis through the polarity and subjectivity of the answers; and (3) vector analysis with WordEmbedding to distinguish the top of the close words.

\section{Results}

\subsection{Polarity Analysis}

Polarity concentrates its values within interval $[-1.0,1.0]$. In this study, 0.1147 polarity was obtained, which describes a positive but low feeling. A great majority of interviewees who explained did so under the symptomatology of the disease; however, during this process, they considered the Bible through the writings of Psalm 23 as a source of strength and hope. Thus, the relevant comments of the interviewees are described, classified into positive and negative in Table 2. 
Table 2. Described polarity of each interviewee.

\begin{tabular}{|c|c|c|}
\hline Interviewee & Positive Factor & Negative Factor \\
\hline 01 & $\begin{array}{l}\text { I felt better, encouraged, prayed, and read the Bible; from } \\
\text { that moment on, I felt that the Lord lifted me up. }\end{array}$ & I became scared because I thought I was going to be in a hospital. \\
\hline 02 & $\begin{array}{l}\text { When you read the Bible, you are in contact with God } \\
\text { and you feel good. }\end{array}$ & $\begin{array}{l}\text { I felt that I was choking; they were anguishing moments because } \\
\text { my chest hardened, and part of my throat was like a knot. }\end{array}$ \\
\hline 03 & I feel that God is with me. & $\begin{array}{l}\text { It was complicated with so much illness that I already had; later, } \\
\text { they told me that I had COVID-19. }\end{array}$ \\
\hline 04 & $\begin{array}{l}\text { Meditating on Psalm } 23 \text { generates much self-confidence } \\
\text { because, no matter how difficult the road is, I will always } \\
\text { be there with God's help. }\end{array}$ & It generated a bit of anxiety and despair. \\
\hline 05 & $\begin{array}{l}\text { I believe in God, and I believe that he is the only one who } \\
\text { can provide and save us from all the difficulties that arise } \\
\text { in our lives. }\end{array}$ & $\begin{array}{l}\text { It affects me a lot because they isolate me, push me away, and I feel } \\
\text { unsociable. }\end{array}$ \\
\hline 06 & $\begin{array}{l}\text { You can feel tranquility, a lot of peace, and confidence that } \\
\text { there is someone powerful who is by your side, taking care } \\
\text { of you, supporting you, and guiding your path. }\end{array}$ & $\begin{array}{l}\text { I felt very distressed; I felt very afraid. My boss where I work } \\
\text { passed away. A lot of worries, and my mind was filled with a lot of } \\
\text { anguish and doubts. }\end{array}$ \\
\hline 07 & $\begin{array}{l}\text { We know that the great Pastor, our Lord, is on our side and } \\
\text { that He will always seek our benefit. }\end{array}$ & $\begin{array}{l}\text { I felt fear due to the amount of information that is generated } \\
\text { regarding the disease. }\end{array}$ \\
\hline 08 & $\begin{array}{l}\text { The Lord has been there accompanying us, taking care of } \\
\text { us, and showing us mercy. }\end{array}$ & We were locked up and very sad. \\
\hline 09 & $\begin{array}{l}\text { It makes one feel at peace and calm because He says that } \\
\text { He is our Pastor who will Pastor us and take care of us. }\end{array}$ & $\begin{array}{l}\text { It was a little scary, but at the same time, it said that my body was } \\
\text { not yet ready to die. }\end{array}$ \\
\hline 10 & $\begin{array}{l}\text { I was very cautious not to be too close to people. I had to } \\
\text { work sick since I was paid by the day. }\end{array}$ & Yes, it makes me very insecure. \\
\hline
\end{tabular}

On the other hand, subjectivity is a floating value within the range of $[0,1]$ where 0 is objective, and 1 is subjective. In this research, 0.4753 was obtained. This is considered to be a subjective sentence, being in the middle point of both polarities, where interviewees expressed many personal feelings, views, beliefs, opinions, allegations, desires, beliefs, suspicions, and speculations. Semantic analysis of the interviews allowed for us to understand the interviewees' intention by highlighting essential aspects of their experience as a COVID patient by identifying key phrases called CODE. This allows for knowing the valuation of that phrase and the repeated phrases. This analysis, called text mining, is supported in obtaining conclusive data and in predicting future behaviors.

Figure 3 details the frequency of the most frequently used words during the interviews conducted with COVID-19 patients. These words were organized into the code groups used in interpreting these interviews; in total, six iterations of questions were asked.

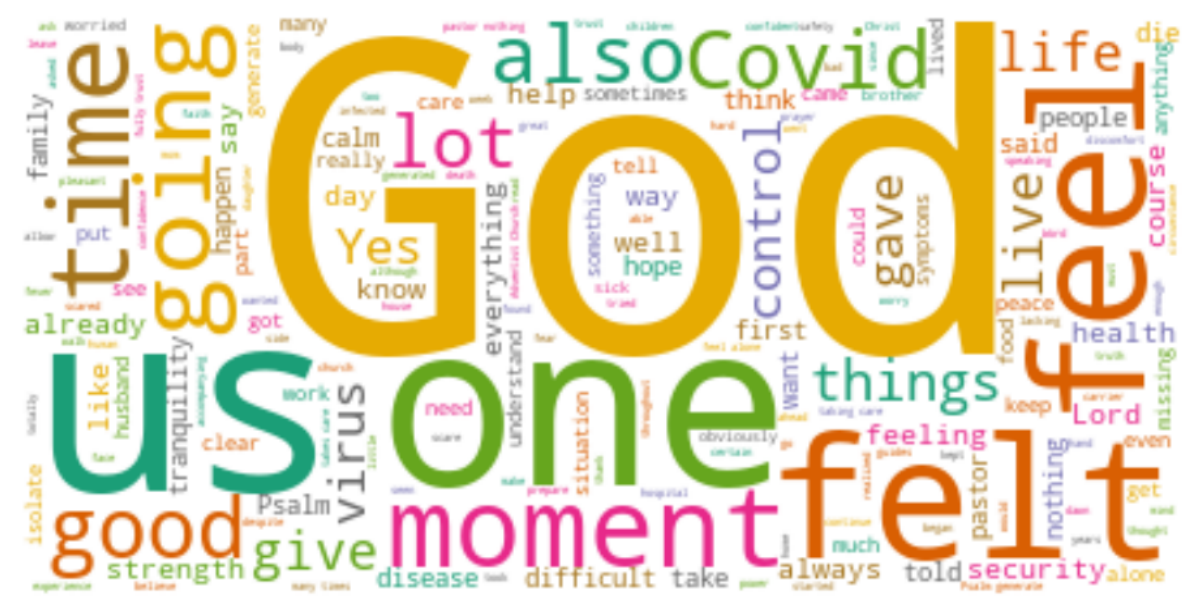

Figure 3. Word cloud from interviews COVID-19 patients.

\subsection{Word Embedding}

The word-embedding technique was used to analyze the conducted interviews with patients suffering from COVID-19. Analysis consisted of finding semantically significant words known as core words. 
The first core word found was the name of the disease, COVID-19, which, according to Table 3, shows the words "experience" and "God" as the closest, which could describe a possible positive experience during the recovery process and obtaining life lessons thanks to confidence in the recovery provided by God.

Table 3. Closest words of COVID-19.

\begin{tabular}{cc}
\hline Word: COVID-19 & Distance \\
\hline Experience & 0.475787 \\
\hline God & 0.4549696 \\
\hline Had & 0.437233 \\
\hline Breathe & 0.40551 \\
\hline Sick & 0.38778 \\
\hline
\end{tabular}

The next central word was "feeling"; Table 4 shows that the words closest to "feeling" were "chest" and "God", which could indicate the sector of the body where the symptomatology of the disease was most suffered. The word "God" is close to the words "COVID-19" and "feel", which could mean that their belief in God helped them in their recovery process.

Table 4. Feel's closest words.

\begin{tabular}{cc}
\hline Word: Feel & Distance \\
\hline Chest & 0.46393 \\
\hline God & 0.42393 \\
\hline Drowned & 0.39776 \\
\hline Totally & 0.3949898 \\
\hline Moments & 0.38685 \\
\hline
\end{tabular}

The penultimate found central word was "disease" (see Table 5). The words closest to "disease" were "clinic" and "week", which could indicate the place where the patients went in critical moments of their disease, and a week is the reference to know the condition and complexity of the disease according to the week of convalescence; it also describes how complicated those weeks of symptomatology were, expressed in their situation. This was a desperate factor for the interviewed patients.

Table 5. Closest words to "disease".

\begin{tabular}{cc}
\hline Word: Disease & Distance \\
\hline Clinical & 0.37554 \\
\hline Week & 0.35245 \\
\hline God & 0.33301 \\
\hline Situation & 0.31012 \\
\hline Drowned & 0.3074848 \\
\hline
\end{tabular}

The last found central word was "Pastor", see Table 6. The words closest to "Pastor" were "control" and "felt", which could describe the patient's sense of confidence in understanding that the Pastor is in control of this disease, allowing for the patient to have "felt" peace of mind knowing that the person they trust would give them healing. This feeling also allows for the patient to emotionally control their thoughts and complex situation. In this situation of convalescence, this is vital for their healing. 
Table 6. Closest words to "Pastor".

\begin{tabular}{cc}
\hline Word: Pastor & Distance \\
\hline Control & 0.40255 \\
\hline Felt & 0.38067 \\
\hline Speaking & 0.36152 \\
\hline Could & 0.354373 \\
\hline Occasions & 0.34321 \\
\hline
\end{tabular}

Table 3 describes the "experience" and "God" words as the closest to "COVID-19", highlighting it as a positive experience despite the symptomatology due to trust in God.

Table 4 describes the "chest" and "God" words as the closest to the word "feel", which is relevant to the sector of the body where symptoms of the disease are suffered the most. However, as observed in Table 3, the attitude was fundamental, which was very positive thanks to the God they trusted.

Table 5 describes the "clinic", "week", and "God" words as closest to "Illness", where the place of recovery of the patient is described if their condition was complicated, and the periods of complications and attitude were fundamental, which was very positive thanks to their God in whom they trusted. Likewise, the last two describe how complicated these weeks of symptomatology were, expressed in their drowning situation, which was desperate for the interviewed patients.

Table 6 describes the words in the text corpus closest to the word "Pastor", which was "control", "felt", "talking", "could", and "occasions". This signified how important it was for the interviewed patients to believe that the main character in Psalm 23, the Pastor (Jesus), was in control of their illness; they felt that, when they spoke to the Pastor through prayers, pleading for healing, the Pastor listened to their needs, trusting that they would be able to excel on challenging occasions of the situation from very complicated occasions.

\subsection{Interview Coding}

In this section, a group of key phrases identified in the interviews (called codes) were grouped into a word that conceptualized and categorized that group (Code group). These words that conceptualized each group of codes were as follows.

\subsubsection{Family Support}

This denotes members who accompanied patients during their recovery process, and provided emotional support and help in their healing process. This support during the disease is explained by four key phrases obtained from the interviews, which are described in Table 7:

Table 7. Code group: family support.

\begin{tabular}{|c|c|}
\hline Code & Code Group \\
\hline The company of my family members at these critical moments & Family support \\
\hline Concern about affecting (infecting) your family & Family support \\
\hline In family company, it is possible to get ahead and not feel lonely & Family support \\
\hline $\begin{array}{l}\text { Since the whole family was infected, they were able to get by together and move } \\
\text { forward without feeling alone. }\end{array}$ & Family support \\
\hline
\end{tabular}

\subsubsection{COVID-19 Emotions}

This consisted of the emotions and circumstances produced by the whole disease process and explained in three key phrases obtained from the interviews, which are described in Table 8. 
Table 8. Code group: COVID-19 emotions.

\begin{tabular}{cl}
\hline Code & Code Group \\
\hline He felt companionship from his family and God, yet there was sadness. & COVID-19 emotions \\
\hline Because of isolation, one becomes lonely; being ostracized by others. & COVID-19 emotions \\
\hline Concern about what generates the illness and distress. & COVID-19 emotions \\
\hline
\end{tabular}

\subsubsection{COVID-19 Uncertainty}

The disease is described according to the uncertainty that it causes. Because of how new the disease was and how changeable the symptoms were, not having a pattern of reaction of the body and not knowing how the immunological condition of the person generated uncertainty in patients. This is explained in three key phrases obtained from the interviews, which are described in Table 9:

Table 9. Code group: COVID-19 uncertainty.

\begin{tabular}{cc}
\hline Code & Code Group \\
\hline This being a new and deadly disease, in many there were no symptoms. & COVID-19 uncertainty \\
\hline Concern about what the disease generates. & COVID-19 uncertainty \\
\hline $\begin{array}{c}\text { Awareness of the disease, considering how the disease being aggravated can be } \\
\text { uncertain. }\end{array}$ & COVID-19 uncertainty \\
\hline
\end{tabular}

\subsubsection{Religious Resilience}

Thanks to the belief and faith of the COVID-19 patients in a God, a supernatural being who has control over all the events of his followers, a positive attitude was produced that helped them to overcome the trial and conditions of the disease. This is explained in 12 key phrases obtained from the interviews, which are shown in Table 10.

Table 10. Code group: religious resilience.

\begin{tabular}{|c|c|}
\hline Code & Code Group \\
\hline Security that God is the one who controls the universe and thereby humanity. & Religious resilience \\
\hline $\begin{array}{l}\text { Despite the difficulty of the disease, one manages to have security in God and } \\
\text { his promises. }\end{array}$ & Religious resilience \\
\hline $\begin{array}{l}\text { Sense of calmness due to trust in God; however, there were moments of worry } \\
\text { (anguish) due to symptoms. }\end{array}$ & Spiritual resilience \\
\hline $\begin{array}{l}\text { Convinced that God is on your side. For that reason, the promise of Psalm } 23 \\
\text { lead to the belief that God will heal them (I shall not want). }\end{array}$ & Spiritual resilience \\
\hline Confidence that God is in control of everything. & Spiritual resilience \\
\hline Denotes tranquility under challenging times. & Spiritual resilience \\
\hline $\begin{array}{c}\text { Confidence that God is in control of everything, having the assurance that he } \\
\text { can restore. }\end{array}$ & Spiritual resilience \\
\hline $\begin{array}{l}\text { The desire to fight and makes discouraging and negative thoughts of dying } \\
\text { impossible. }\end{array}$ & Spiritual resilience \\
\hline Peace and tranquility as reasons to fight because of being in God's hands. & Spiritual resilience \\
\hline $\begin{array}{l}\text { Promise that security and desire are generated to continue fighting with God's } \\
\text { help. }\end{array}$ & Spiritual resilience \\
\hline $\begin{array}{c}\text { Confidence that God is in control, guiding life physically, mentally, } \\
\text { and spiritually. }\end{array}$ & Spiritual resilience \\
\hline $\begin{array}{c}\text { Trusting in God and knowing that one can cling to him, one does not think } \\
\text { of death. }\end{array}$ & Spiritual resilience \\
\hline
\end{tabular}

\subsubsection{Diagrams of Occurrence Codes and Interviewees}

Figures 4 and 5 graphically represent the flow of the dimensions (code groups) to the respondents; both figures show the data flow among the different code groups and 
their volume in a proportional manner. The volume is constituted as the magnitude of the relationship between the code groups and is represented by arrows; the larger the arrow is, the greater the magnitude of the relationship. According to data variation, arrows were combined using different colors; the arrows completed their connection through points in common between code groups and respondents. Reports show how the code groups and their frequency are related to each interviewee; some arrows were thicker than others, which means that some code groups were more predominant.

Figures 4 and 5 illustrate the occurrences among the codes identified in the interviews in the interviewees, i.e., the width of the flows describes the proportionality of the number of occurrences of codes that the interviewees used.

Figure 4 shows that spiritual resilience stands out the most from all the key sentence codes. Respondent 4 mentioned it the most in his answers, which is expressed by quantity flow 4. For example, he said: "no matter how difficult the road is, at the end of the day I am in God's hands"; this phrase expresses the resilience that trust in God can generate. Likewise, words such as security, confidence, tranquility, and peace were used by this interviewee, which could have helped him to take a different attitude against the symptoms and complications of his disease.

In second place are emotions produced by COVID-19, for example, Interviewees 1 and 5 this group; one of the phrases of Interviewee 1 stands out: "I felt sadness and depression, and more than everything it was depression; there were moments when I cried and felt very alone".

Figure 5 shows resilience in first place; Interviewees 6 and 7 mentioned this code group the most. For example, Interviewee 6 said: "I consider that God is in control of everything, even my health"; interviewee 07 agreed with the following phrase: "the great Pastor our Lord is on our side and will always seek our benefit".

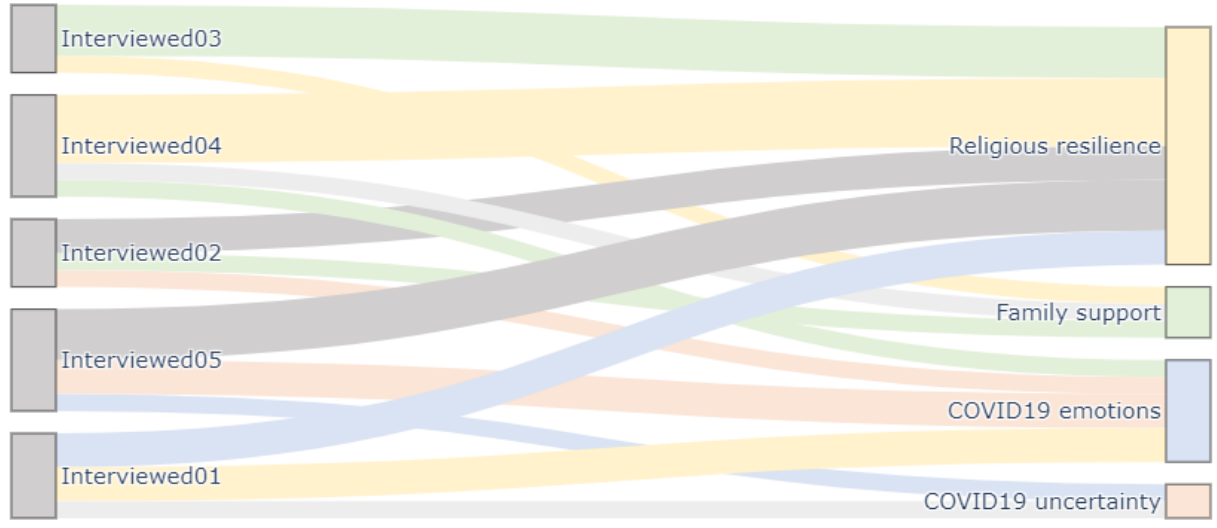

Figure 4. Sankey diagram-occurrence code groups with Respondents 1-5.

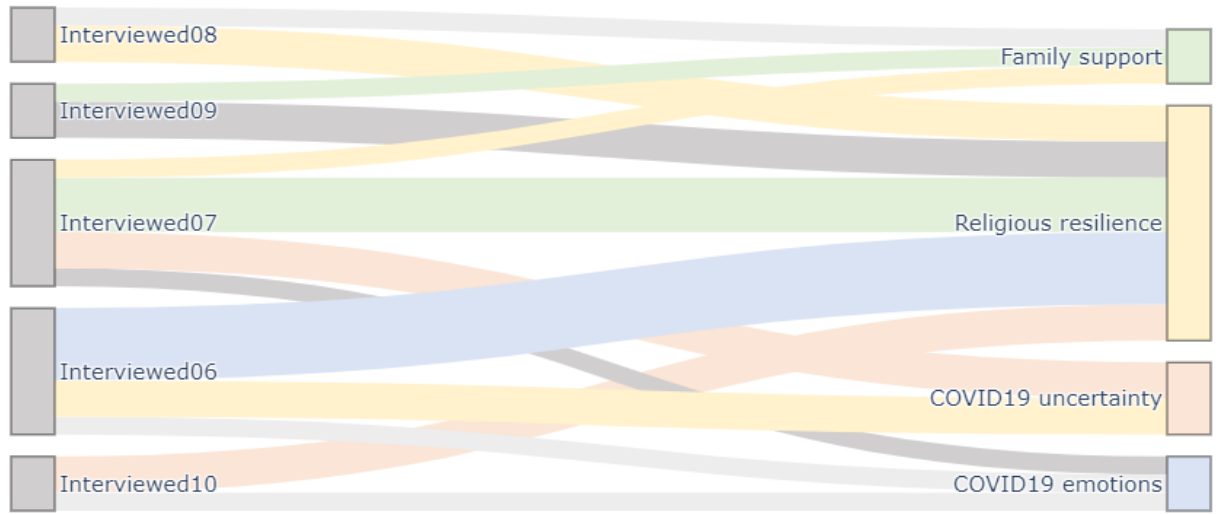

Figure 5. Sankey diagram-occurrences code groups with Respondents 6-10. 


\section{Discussion}

Resilience is the ability to adapt to adverse situations. Codes of resilience favor the concept of spiritual resilience because it is evident that there are factors related to God that help them to adapt to adverse situations; the factor that most contributes to the generation of resilience is the presence of God and security in him.

Can spiritual resilience be evidenced in the respondents' answers? In addition, are our security and trust in God, and divine presence the factors in respondent answers that favor the concept of spiritual resilience? Respondents were 10 COVID-19 patients from Ecuador and Colombia, aged between 25 and 84 years; 5 males and 5 females. Inclusion criteria: belonging to the Christian religion, and being a recovering COVID-19 patient or having recently recovered. The company of God is the most predominant theme in the structure of Psalm 23. YHWH is the Pastor who makes it so that nothing is lacking, and that people have peace and security. The Pastor's care for his flock is fundamental. One of the main tasks of the Pastor is to care for each of his sheep without exception, giving all his effort to guide, protect, heal, and accompany; by doing this, he demonstrates his meticulous work with an expression of love. In fact, the thematic center of the psalm is "God is with me"; therefore, this concept of God's presence makes it possible for the patient to generate resilience to face their crisis by being aware of the divine presence and the effects of this presence on them.

Which words or concepts from the 12 key phrases affirm the presence of God? Here, we compare the keywords or concepts of Psalm 23 under the respondents' concept of God's presence (resilience). Codes of Table 10 show security in codes 1, 2, 7, and 10; and peace in codes 3,6,9, affirming the presence of God, as these effects are the product of divine presence, so to speak,. Similarly, in Psalm 23, the effects that confirm God's presence are peace, rest, comfort, security, and a hopeful future. These effects in the psalm are produced solely by God's presence.

What words or concepts in the 12 codes contrast or threaten God's presence? Here, we compare keywords or concepts in Psalm 23 that David considers threatening, which makes him resilient from the perspective of hope and security because of God's presence. Resilience codes (Table 9) showed life-threatening factors. Among these, in codes 2 and 3 , illness and its symptoms were identified as a threatening factor, while in codes 8 and 012, it was death. It is no coincidence that the life of human beings is almost always under different threats, as was the case of the author of Psalm 23, who also felt his life threatened by "walking in a valley of the shadow of death", being persecuted and besieged by anxious people. Undoubtedly, the threats in question vary in the context of place and type, but the threat to life remains latent. However, a common factor that generated resilience in the face of the different threats was the security because of the presence of God.

Which words or concepts of the 12 respondents affirm God's presence in the future? Here, we compare keywords or concepts from Psalm 23 that describe future security in God. None of the resilience codes (Table 9) supported the affirmation of God's presence in the future. Instead, they supported the assertion of God's immediate presence because it is necessary at moments of crisis; the resilience caused by God's presence is necessary to cope with negative factors. In the same way, in Psalm 23, God's presence is in the present: "You are at my side" (present).

\section{Conclusions}

Analyzed text mining showed how important attitude towards a crisis is for a convalescent patient, described by the factors of spiritual resilience. Spiritual resilience stood out the most in all thekey sentence codes, for example, "No matter how difficult the road is, at the end of the day, I am in God's hands". This phrase expresses the resilience that trust in God can generate. Likewise, words such as security, trust, tranquility, and peace allowed for a different attitude to face the symptoms and complications of the disease. This is due to the factor of trust and belief that they have, which helps to control these periods of crisis. 
Therefore, it is proposed to continue researching these topics where studies can be formulated for future work to help reduce the social impact of any future crisis, and to analyze in extracted opinions from sources such as social networks and interviews the related factors to good practices and stories that allowed for people to withstand such situations, experiences that offer improvements and solutions to such problems. Languagelearning computer databases to propose should also be generated as self-help systems to people who suffer severe crises.

Author Contributions: Conceptualization, M.P.-F., V.C.-S., Y.F.-T., J.P.-P. and J.S.-G.; methodology, H.A.-G., J.L.L.-G. and J.S.-G.; software, J.S.-G.; validation, J.S.-G. and J.L.L.-G.; formal analysis, J.L.L.-G. and H.A.-G.; investigation, J.S.-G.; writing—original draft preparation, J.L.L.-G., J.S.-G. and H.A.-G.; writing —review and editing, H.A.-G., J.L.L.-G. and J.S.-G.; visualization, J.S.-G. and J.L.L.-G.; supervision, J.S.-G. All authors have read and agreed to the published version of the manuscript.

Funding: This research received no external funding.

Institutional Review Board Statement: Not applicable.

Informed Consent Statement: Not applicable.

Data Availability Statement: Not applicable.

Conflicts of Interest: The authors declare no conflict of interest.

\section{References}

1. Tan, L.; Yu, K.; Bashir, A.K.; Cheng, X.; Ming, F.; Zhao, L.; Zhou, X. Toward real-time and efficient cardiovascular monitoring for COVID-19 patients by 5G-enabled wearable medical devices: A deep learning approach. Neural Comput. Appl. 2021, 1-14. [CrossRef]

2. Praveen, S.V.; Ittamalla, R.; Deepak, G. Analyzing Indian general public's perspective on anxiety, stress and trauma during COVID-19-a machine learning study of 840,000 tweets. Diabetes Metab. Syndr. Clin. Res. Rev. 2021, 15, 667-671. [CrossRef]

3. Lahiri, A.; Jha, S.S.; Acharya, R.; Dey, A.; Chakraborty, A. Correlates of insomnia among the adults during COVID-19 pandemic: Evidence from an online survey in India. Sleep Med. 2021, 77, 66-73. [CrossRef]

4. Nguyen, H.C.; Nguyen, M.H.; Do, B.N.; Tran, C.Q.; Nguyen, T.T.P.; Pham, K.M.; Pham, L.V.; Tran, K.V.; Duong, T.T.; Tran, T.V.; et al. People with Suspected COVID-19 Symptoms Were More Likely Depressed and Had Lower Health-Related Quality of Life: The Potential Benefit of Health Literacy. J. Clin. Med. 2020, 9, 965. [CrossRef]

5. Breen, L.J.; Lee, S.A.; Neimeyer, R.A. Psychological Risk Factors of Functional Impairment After COVID-19 Deaths. J. Pain Symptom Manag. 2021, 61, e1-e4. [CrossRef] [PubMed]

6. Steardo, L.; Steardo, L.; Verkhratsky, A. Psychiatric face of COVID-19. Transl. Psychiatry 2020, 10, 261. [CrossRef]

7. Salas-Zárate, M.D.P.; Medina-Moreira, J.; Lagos-Ortiz, K.; Luna-Aveiga, H.; Rodriguez-Garcia, M.A.; Valencia-Garcia, R. Sentiment analysis on tweets about diabetes: An aspect-level approach. Comput. Math. Methods Med. 2017, 2017, 5140631. [CrossRef]

8. Alamoodi, A.; Zaidan, B.; Zaidan, A.; Albahri, O.; Mohammed, K.; Malik, R.; Almahdi, E.; Chyad, M.; Tareq, Z.; Albahri, A. Sentiment analysis and its applications in fighting COVID-19 and infectious diseases: A systematic review. Expert Syst. Appl. 2020, 167, 114155. [CrossRef] [PubMed]

9. Chakraborty, K.; Bhatia, S.; Bhattacharyya, S.; Platos, J.; Bag, R.; Hassanien, A.E. Sentiment Analysis of COVID-19 tweets by Deep Learning Classifiers-A study to show how popularity is affecting accuracy in social media. Appl. Soft Comput. J. 2020, 97, 106754. [CrossRef]

10. Sun, N.; Wei, L.; Wang, H.; Wang, X.; Gao, M.; Hu, X.; Shi, S. Qualitative study of the psychological experience of COVID-19 patients during hospitalization. J. Affect. Disord. 2021, 278, 15-22. [CrossRef] [PubMed]

11. Koh, J.X.; Liew, T.M. How loneliness is talked about in social media during COVID-19 pandemic: Text mining of 4492 Twitter feeds. J. Psychiatr. Res. 2020. [CrossRef] [PubMed]

12. Kaur, S.; Kaul, P.; Zadeh, P.M. Monitoring the Dynamics of Emotions during COVID-19 Using Twitter Data. Procedia Comput. Sci. 2020, 177, 423-430. [CrossRef]

13. Garcia, K.; Berton, L. Topic detection and sentiment analysis in Twitter content related to COVID-19 from Brazil and the USA. Appl. Soft Comput. 2021, 101, 107057. [CrossRef]

14. Barkur, G.; Vibha; Kamath, G.B. Sentiment analysis of nationwide lockdown due to COVID 19 outbreak: Evidence from India. Asian J. Psychiatry 2020, 51, 102089. [CrossRef] [PubMed]

15. Laconi, S.; Ramaye, D.; Kalaitzaki, A. Psychological impact of the COVID-19 pandemic: Comparison between residents of metropolitan France and of Reunion Island. L'Encéphale 2021. [CrossRef]

16. Bhat, M.; Qadri, M.; Noor-ul-Asrar Beg, M.K.; Ahanger, N.; Agarwal, B. Sentiment analysis of social media response on the covid19 outbreak. Brain Behav. Immun. 2020, 87, 136. [CrossRef] 
17. Ayoub, J.; Yang, X.J.; Zhou, F. Combat COVID-19 infodemic using explainable natural language processing models. Inf. Process. Manag. 2021, 58, 102569. [CrossRef] [PubMed]

18. Gupta, V.; Jain, N.; Katariya, P.; Kumar, A.; Mohan, S.; Ahmadian, A.; Ferrara, M. An emotion care model using multimodal textual analysis on COVID-19. Chaos Solitons Fractals 2021, 144, 110708. [CrossRef]

19. Johns Hopkins University. COVID-19 Map-Johns Hopkins Coronavirus Resource Center. Available online: https://coronavirus. jhu.edu/map.html (accessed on 20 August 2021).

20. Martínez, M. Ciencia y Arte en la Metodología Cualitativa; Trillas: Mexico City, Mexico, 2004; p. 354. [CrossRef]

21. Colaizzi, P.F. Psychological research as the phenomenologist views it. In Existential-Phenomenological Alternatives for Psychology; Valle, R.S., King, M., Eds.; Oxford University Press: Oxford, UK, 1978; p. 6.

22. Chen, M.C.; Ho, P.H. Exploring technology opportunities and evolution of IoT-related logistics services with text mining. Complex Intell. Syst. 2021, 7, 1-19. [CrossRef]

23. Behl, S.; Rao, A.; Aggarwal, S.; Chadha, S.; Pannu, H.S. Twitter for disaster relief through sentiment analysis for COVID-19 and natural hazard crises. Int. J. Disaster Risk Reduct. 2021, 55, 102101. [CrossRef]

24. Lee, C.; Jeon, D.; Ahn, J.M.; Kwon, O. Navigating a product landscape for technology opportunity analysis: A word2vec approach using an integrated patent-product database. Technovation 2020, 96-97, 102140. [CrossRef]

25. Bansal, B.; Srivastava, S. Sentiment classification of online consumer reviews using word vector representations. Procedia Comput. Sci. 2018, 132, 1147-1153. [CrossRef]

26. Bai, Y.; Zhao, L.; Wang, Z.; Chen, J.; Lian, P. Entity Thematic Similarity Measurement for Personal Explainable Searching Services in the Edge Environment. IEEE Access 2020, 8, 146220-146232. [CrossRef]

27. Yadollahi, A.; Shahraki, A.G.; Zaiane, O.R. Current state of text sentiment analysis from opinion to emotion mining. ACM Comput. Surv. 2017, 50, 1-33. [CrossRef]

28. Medhat, W.; Hassan, A.; Korashy, H. Sentiment analysis algorithms and applications: A survey. Ain Shams Eng. J. 2014, 5, 1093-1113. [CrossRef]

29. Hatzivassiloglou, V.; McKeown, K.R. Predicting the semantic orientation of adjectives. In Proceedings of the 35th Annual Meeting of the Association for Computational Linguistics and 8th Conference of the European Chapter of the Association for Computational Linguistics, Madrid, Spain, 7-11 July 1997; pp. 174-181. 